\title{
Gender Diversity: \\ To Be Managed or Not?
}

\author{
Manuel Brugger
}

Abertay University, United Kingdom

\begin{abstract}
:
The purpose of this paper is to examine women's perceptions of the manufacturing industry in the UK. More specifically, the research analyses factors influencing women's decision on pursuing a career in the manufacturing industry at a Multinational Company. The findings indicate that the factors impacting women to pursuing a career in manufacturing are underlined by a complex interrelated system and depend on both societal and organisational patterns of behaviours, values and norms. Insights of this are particularly useful for managers and organisations operating in the manufacturing industry. The study suggests underlying reasons and implications that can be implemented. This study is based on a convenience sample and cannot be treated as a representative for the entire UK manufacturing industry.
\end{abstract}

Paper type: Research paper

Keywords: Gender Diversity, Organisational Culture, Employer Branding 


\section{Introduction}

Over the four decades, the number of women participate in the UK labour workforce has increased by $14 \%$. According to the Office for National Statistics (2013), the amount of employed women in the UK in the age bracket of 16 to 64 has significantly increased from 53\% in 1971 to $67 \%$ in 2013. In 2012, women comprised $45.9 \%$ of the overall labour force in the UK (The World Bank 2014). The tendency of growing female population among the gender composition within the workforce suggests a changing role of women at workplace. Reasons for this historical development were interpreted as a result of cultural changes originating from social trends that have evolved over the past decades (Sharabi and Harpaz 2013). Despite the fact that the number of women is on the rise, women are underrepresented in particular sectors including the manufacturing industry (Lawthom et al. 1996). The manufacturing industry is generally associated with heavy and dirty work, which seems to enforce common perception that women are not suitable to work in manufacturing industry.. Although the UK government have introduced several initiatives in order to encourage women to pursue a career in a traditionally male-dominated area, there has not been a significant transition.

\section{Analytical view of gender diversity}

\subsection{Emergence of gender bias}

As the amount of working women increased and firms began to value their contribution to the firms' success, the term gender diversity emerged and consolidated over the last decades. Gender diversity describes the tendency of women being represented in different professions and within various industries and may occur on any hierarchical level within a firm. Beyond gender distribution, it further contains the acceptance and reinforcement of gender based equal employment objectives. Reskin and Bielby (2005) argue that men and women position themselves in different firms or concentrate on certain jobs within particular organisations. This imbalance in the number of men and women working in an establishment is generally attributed to gender bias and results from different reasons.

\subsection{Women's professional path}

Throughout their course of life, men and women make different choices that pave the way for their future careers. Beginning at secondary school, individuals of both gender, group themselves in different field of interests by choosing different classes and correspondingly different study courses that may result in diverse career opportunities in certain industries (Correll 2001). However, this disparity based on educational level should not hinder females to follow another career. Graduates from a specific degree are not obligated to follow a career derived from their study subject. Therefore, they may find an occupation in various domains not referring to their acquired expertise. Peacock (2011) reports that one out of seven graduates from the UK in 2010 who completed his

International Journal of Management and Applied Research, 2015, Vol. 2, No. 1 
or her degree in science, engineering and technology chose to work in another sector, not related to the field of study. These early decisions raise the question of their cause of origin. What factors are responsible for individuals' motives and ambitions in the course of their professional paths?

According to Barbulescu and Bidwell (2012), men and women make career choices based on their gender role beliefs, which may be seen as a reason for disparity in this industry. Gender beliefs seem to derive from their own perceptions on abilities and behaviour rooted in gender and seems to be a determining factor in their choice of career. Historically, the profession of manufacturing has been stereotyped as repetitive, low skilled, and in need of physical work. Powell et al. (2004) describe it as dull and consisting of non-creative work. Over the years, these beliefs have stayed persisted and reinforce the assumption that women are unsuitable to work in the manufacturing industry (Evetts 1998). Whereas historical perceptions may lead to misunderstandings, as technology with computers and automation seem to require well-educated employees, Evetts (1998) states that females tend to encounter difficulties with being part of the organisational culture in the manufacturing industry even though they seem to succeed in dealing with the industry related work.

\subsection{Organisational culture}

In the context of this study, organisational culture is created by employees and defined by their practices and shared meanings such as values, assumptions and beliefs that are expressed in the style of management, work philosophies, language and communication as well as temporal structuring of work (Rutherford 2001). Based on these components, organisational culture defines a set of behaviours and practices and determines the integration or exclusion of employees from affiliation. Underlying reasons for an inclusion or exclusion could therefore imply a particular type of organisational culture and suggest a possible impact of leadership, which is introduced in the following section.

\subsection{Organisational fit}

Besides facing stereotypes, there are certainly cases where the proportion of women in the working environment may be a crucial point on a woman's "sense of fit" within the organisation (Simpson 2000). Organisational fit describes a situation where an employee feels comfortable or uncomfortable in the environment of an organisation. As Simpsons (2000) argues, women tend to experience partial or poor organisational fit in organisations that are dominated by male values, such as 'competitive', 'aggressive' and 'macho'. However, this cannot be generalised as other factors within various organisations and different environments need to be considered and evaluated. Another point of view is described in the conceptual model of person-organisation (P-O) fit, which involves the compatibility between an employee and an organisation he or she works in. It is further argued that the model implies multiple suggestions for possible

International Journal of Management and Applied Research, 2015, Vol. 2, No. 1 
outcomes at the workplace concerning organisational attraction, job choice, job satisfaction, organisational commitment and turnover (Kristof 1996).

Piasentin and Chapman (2006) classify P-O fit into four categories. The first category is named 'supplementary fit', where the characteristics of an individual are similar to the existing characteristics of an organisation. A 'Complementary fit' occurs when an individual contributes to an organisation by filling voids or odds. The third category, named 'needs-supplies fit', is presented, when an individual's needs are met by the organisation. In contrast to this, when an individual's abilities meet the demands of an organisation, it can be defined as a 'demand-abilities fit'. However, the study of Arthur, Bell and Villado (2006) showed results of a meta-analysis on criterion-related validity of P-O fit suggest that the model of P-O fit is not a good predictor of job performance. Nevertheless, due to strong correlations with work attitudes, it is further argued that the model could be used as a predictor of turnover. This suggests a consideration and analysis of $\mathrm{P}-\mathrm{O}$ fit, as it seems to be a relevant and promising factor of integration and job satisfaction. Furthermore, evaluations of P-O fit in a particular company might lead to an understanding of reasons for career choices and organisational values.

Although decisions of job applicants and recruiters conduce a $\mathrm{P}-\mathrm{O}$ fit when a new employee joins the company, P-O fit also may take more time and evolve through socialisation. The term socialisation describes the process of a person acquiring organisational attitudes, informal and formal rules of behaviour as well as sets of knowledge. Socialisation therefore serves as a concept ensuring continuation of an organisation's core values and fundamental norms (Cable and Parsons 2001). According to Sherman and Chatman (2013), an individual learns critical information about the company he or she joined and responds in various ways. Hence, socialisation determines two distinct courses of events. One possibility is that an individual adapts to the organizational values in order to attain congruence with the expectations of colleagues. Another possible outcome refers to incompatibility, where an individual cannot integrate him- or herself resulting in isolation or even resignation.

\subsection{Women in manufacturing}

Despite the improvements in terms of gender diversity women have experienced, negative beliefs and stereotypes of women in leading positions are still present (Jackson 2001; Fernandes and Cabral-Cardoso 2003). Attitudes based on prejudices towards female managers contain assumptions of women being less suitable than men for managing positions. Beliefs that the characteristics of a manager are shaped by masculine attributes seem to result in less women in management (Burke and Collins 2001). A study by Deloitte and the Manufacturing Institute (2012) supports this thought by arguing that one of the main drives for women's underrepresentation in the manufacturing industry is the perception of a male-favoured culture. Nevertheless, other

International Journal of Management and Applied Research, 2015, Vol. 2, No. 1 
research implies that culture has no significant impact on influencing attitudes and beliefs towards female leaders (Cordano et al. 2002).

The perception of women not being welcomed in the manufacturing industry may be affected by gender inequality in context of their salaries. A report from the International Trade Union Confederation (Tijdens and Van Klaren 2012) found that the manufacturing industry has the fourth largest salary gap among all industries. More specifically, women are paid on global average $18 \%$ less compared to men for a comparable job. If the gender pay gap is due to an observable distinction of person's capabilities such as level of education, work experience or other skills, it will be accepted or not even perceived. In contrast, if the gender gap arises as a consequence of inexplicable factors endorsing inequality, internal and external concerned individuals may be negatively affected (Khoreva 2011). Such conditions may discourage women from applying to positions on any hierarchal level within the firm. Further research on the impact of a salary that is more gender equal, showing the appreciation of female's contribution in the manufacturing industry is recommended and may reveal a positive impact on women's perception.

\subsection{Relevance of gender bias}

In the last twenty years, the study and analysis of workplace diversity in the field of businesses has increased in its relevancy (Tatli 2006). Gender diversity became a major aspect of modern organisations (Reskin and Bielby 2005).

It is not only an issue related to human resources but also to the corporate business. Identifying and managing the issue of gender diversity seems to enable certain firms to reduce their turnover costs, recruit and maintain high potential employees and make better business related choices. Furthermore, particular firms tend to be more capable in responding to changing marketplaces (Levin and Mattis 2006). Women constituting in staff seem to generate a different range of perspectives, which may add creativity that could be needed when facing complex problems (Kravitz 2003). Empirical studies show that having women on board of executives tends to have positive financial impact within the organisation (Erhardt et al. 2003; Lückerath-Rovers 2013). Similarly, Lenard et al. (2014) found that a good gender balance on management boards appears to result in a lower variability of both corporate performance and stock market return. However, other research (Raluca-Georgiana 2013; Flabbi 2010) found that an increase of the number of women in management positions has no impact on a firm's performance.

\section{Methodology}

To investigate the perception of female workers towards working in manufacturing industry, interviews were conducted. Interview is particularly suitable for this line of inquiry: interpretivism as it ensures understanding of the research participants'

International Journal of Management and Applied Research, 2015, Vol. 2, No. 1 
perspectives (Saunders et al., 2012). More precisely, it allows researchers to focus on the explanation of causes and understandings of their perceptions and behaviour (Bryman 2012).

Because of the confidentiality requirements imposed by the company, the subsidiary of the participating company will be referred to as 'Company A'. Company $\mathrm{A}$ is a leading company in its sector and operates in multiple countries across the world. Eight female employees of Company A were willing to take part in this study. Employees as participants were essential for this research, since they once have passed all the steps from applying and being hired to employment. Concerning the similarities in occupation and gender of these respondents, a non-probability sampling method was used. More precisely, a homogeneous purposive sampling method was chosen, as the research question specifically addresses a particular characteristic of this group of respondents (Saunders et al. 2012). Each employee was interviewed in a meeting room at their factory facilities in order to guarantee a familiar environment.

According to Schwandt (1997), main components of the data analysis are seen in sense making activities such as theorizing and interpreting data. For the data analysis of the interviews, categories defined by the questions asked in the interviews were created. After clarifying the meaning of all the answers given, the data was reorganised and allocated to the corresponding themes. The ethical approval of this study was obtained. For the purpose of confidentiality, each participant was labelled as 'respondent' and a corresponding code represented by a letter from A to $\mathrm{H}$ (e.g. respondent A) was assigned.

The convenience sampling was one of the key limitations as the results cannot be treated as a representative for the entire population. The result rather needs to be seen as a substance occurring within the given sample. Main focus of this research study was aimed at distinct groups in a particular industry, suggesting a 'contextual uniqueness' (Bryman 2012). However, since gender diversity in a male-dominated industry is a frequently discussed and major topic among the boards of organisations, the transferability of the findings may present a relevant exploration for companies operating in similar environments (Bryman 2012; Reskin and Bielby 2005).

\section{The results}

The following themes have emerged from data analysis: Gender biased assumptions, Person-Organisation Fit, Organisational culture as well as Employer branding.

International Journal of Management and Applied Research, 2015, Vol. 2, No. 1 


\subsection{The Gender-biased assumptions theme}

The subject of gender became more and more relevant and it has been discussed in many different contexts. Understanding the origin and cause of gender bias and its potential impact on companies is therefore of increasing importance.

Results showed that female employees tend to have the impression that male colleagues have concerns about women work-related performance. However, gender bias seems to be imposed to a certain degree by female employees. It appears that situations may be interpreted in a biased way leading to possible misunderstandings. According to respondent $\mathrm{H}$, empathizing seems to be a method utilised to "think what male colleagues could think". Such assumption may occur by default and may result in the apprehension that a male colleague acted in a gender biased way. Respondent B indicated that the resulting uncertainty of the actual meaning of an action is "intimidating".

Findings of this research further suggest that female employees tend to believe that their professional knowledge in a particular field of work is unequally valued and men therefore do not expect female colleagues to have an equal expertise. According to Respondent $\mathrm{H}$, it is further suggested that female employees tend to assume that male employees rather approach male colleagues.

As argued in prior studies, women seem to face a variety of societal or organisational barriers preventing them to obtain equal career progression opportunities (Jackson 2001; Fernandes and Cabral-Cardoso 2003; Kravitz 2003). Among others, the phenomena of glass ceiling and stereotyping were discussed as potential reasons (Carli and Eagly 2001). The research findings of this study demonstrate that, to some extent, female employees appeared to assume that their male counterparts are favoured in the career progression process. As implied by respondent B, when new job positions are filled, there is "a lot occurring behind the scenes". Therefore, female employees tend to feel excluded from recruitment disclosures. It can be inferred that this feeling of exclusion leads women to gender biased assumptions of men being favoured in the career progression, might occur due to different reasons. First, insufficient commentary from management might leave space for interpretation and appraisal. Second, it is possible that female employees make gender biased assumptions on the basis of others' influence. As the issue of men being favoured in the promotion process is a topic that arises frequently, it seems natural to avoid the comprehension and acceptance of a decision and follow a gender biased assumption. Then, female employees take a side of an argument by default and promote a commotion in the media without realising a critical consideration.

Another finding is that female employees refer to social interaction patterns. Some female employees tend to believe that male employees treat them differently based on

International Journal of Management and Applied Research, 2015, Vol. 2, No. 1 
their gender rather than their performance. Indicated by respondent $\mathrm{C}$, female employees seem to prefer no special treatment "even though it's a nice gesture", where the gesture did not evidently occur for the reason assumed. Consequently employees appear to carry gender-biased assumptions when interacting with each other.

\subsection{The 'Person-organisation (P-O) fit' theme}

Every organisation has its own distinct culture, which is determined by the behaviour and mind-set of its employees. Hence, in order to be integrated in an organisation, employees need to identify themselves with an existing culture of an organisation. The finding is that open-mindness and being less conservative about certain conditions appear to facilitate a $\mathrm{P}-\mathrm{O}$ fit not the gender.

Respondent $\mathrm{H}$ suggested that there are certain factors that concern female employees within the departments. The statement that everyone can fit in the company if he or she is "not too sensitive and has a sense of humour" implied that particular occurrences should be tolerated in order to fit in the organisation. From another point of view, sensitivity and following initiatives that seek for a change might not be welcomed and employees are more likely to fit in the organisation by accepting current courses of events. According to respondent B, adapting to or opposing to a certain scheme of procedure are the two options that can be followed. These two options may respectively result in the integration or the exclusion of an employee. Respondent D further indicated that the disguise of an employee in order to fit in an organisation can be "stressful", as it is not the "natural way of behaving". Thus, it appears that employees seem to be required to adapt to particular values in order to be fully integrated.

\subsection{The 'Organisational culture theme}

Organisational culture is a key factor when it comes to understanding interpersonal behaviour and collaboration within the company. An organisational culture that creates an impression of containing dismissive attitudes towards women could be a decisive influential factor preventing female job applicants from applying to the company.

The findings indicate that the organisational culture of Company $\mathrm{A}$ is at current stage transforming from a rather conservative to a more liberal organisation. According to respondent $\mathrm{F}$, the organisational culture of Company A implies signs of a "blame culture with rivalry among departments". Respondent A supported this point and indicated that there is a "lack of cross-departmental cooperation". A blame culture can be defined as the unwillingness of an individual or group of people to accept the responsibility for making a mistake in order to avoid criticism or other consequences (Mousumi 2009). In the context of this study, evidence for a partially existing culture of blame might be an indicator for prohibiting a company to be responsive and open to change. The flexibility and willingness to agree to changes can be associated with an organisational transition to an increased proportion of women on staff.

International Journal of Management and Applied Research, 2015, Vol. 2, No. 1 
However, it was further indicated that leadership style of the upper management has changed the organisational culture into a "more liberal and flexible working environment". Therefore it seemed that a certain type of leadership contributed to an organisational change. Similarly, respondent G agreed to the change brought through the "morale" of the upper management and additionally indicated that an organisational change occurred based on the influx of relatively "young employees joining the company". In other words, young people seem to contribute to a more diverse culture promoting the engagement and acceptance of new trends.

\subsection{The Employer branding theme}

One of the aims of the study is to examine the reasons that influence female job applicants to choose Company A as their employer. In the light of this, the brand of a company and the perception of an industry were assumed to be crucial drivers in the decision-making process of choosing to apply for a job position.

However, in the interviews and the discussions on job seeking, it appeared that a considerable number of employees came into contact with the company through various recruitment agencies. This dominating trend of looking for a potential employer suggested that female job seekers tend to choose their employment on the basis of their personal qualifications and educational backgrounds, rather than the branding of a company. Respondent C stated that she "exclusively applied to Company A based on the job description that corresponded to her qualifications and that she did not apply based on this particular industry or company". Similarly, respondent B indicated that the advertised work content is considered to be important, as she "did not look for a specific company, but for a position that fit her skills".

It further appears that driving factors for choosing an employer are seen in career opportunities, job security, remuneration, and overall reputation of a company. Among all respondents in the interviews, no one stated the brand of Company $\mathrm{A}$ as a decisive factor of joining the company. In particular, respondent D described Company A as a "well-known" company that provides a "relatively good salary" and a "relatively secure job". Consistent with respondent F, who considered "training and progression" as the main factors, respondent E sought to keep "learning", "progressing" and "developing in person".

It can be concluded that the perception of the manufacturing industry in terms of employer branding and profile is of minor significance to the applicants. In this regard, suiting job descriptions and opportunities of career progression are the prioritised factors when deciding to join a company.

In summary, the combination of the deeply rooted societal belief of typical roles and statuses and the consistent emphasis of the importance of gender diversity in the society

International Journal of Management and Applied Research, 2015, Vol. 2, No. 1 
is responsible for the commonly assumed perception of a gender biased manufacturing industry. These consequently imposed assumptions of men's stereotyped behaviour are to some extent evitable. A company in the manufacturing industry based in the UK, such as Company A should therefore consider these prevalent, societal beliefs. Being aware of the potentially arising biased assumptions imposed by female employees allows the organisation to reduce or prevent the possibility of such misleading comprehensions. Knowing and understanding the background and reason of the existence and reinforcement of the perception that the manufacturing industry is seen as male-dominated, establishes clarity in respect to the cause of receiving fewer female applications. In fact, the implementation of tailored measures can reduce undesired assumptions and encourage more female applicants to apply.

\section{Conclusion}

The purpose of this study was to identify factors influencing female applicants when applying for a position in a male-favoured industry or manufacturing industry more specifically. To gather an in-depth insight regarding the perceptions of female employees towards the manufacturing industry, interviews were conducted to analyse relevant components that affect an applicant's decision making in the context of their career choices. After examining aspirations and conditions within the organisation and society, managerial implications were suggested based on trends and current stage in business theory.

The key value of this study is to rethink the gender balance in organisations on the basis of female employee's voices about the company and the underlying industry. The analysis of an organisation's expected characteristics that determine an employee's fit and integration from a women's point of view showed that specific permissive personalities who tolerate changes and welcome new concepts are most likely to fit to Company A. Gender as a criteria of fit is of minor significance. Moreover, interpretations of the conducted interviews suggested that gender diversity contributes to a more liberal and open-minded working environment.

Internal as well as external factors were analysed and demonstrated how beliefs and perceptions influence an individual's opinion in the context of gender diversity. It was established how important the culture, leadership, and P-O fit of an organisation can be, as these factors determine a company's values and norms. It was further shown why women are underrepresented in the manufacturing industry in the UK and what barriers and views prevent them from pursuing a career in managing positions. Each identified and discussed theme attempts to clarify aspects of considerations and opens up new as well as challenging research avenues.

Although this study provides insightful information about the perceptions and experiences of female workers who work in a male-favoured industry, there are several research limitations. The findings presented in this study are based on data gathered

International Journal of Management and Applied Research, 2015, Vol. 2, No. 1 
through a limited number of interviews and were inferred from individual perspectives and experiences. Therefore, the generalisability of this study could be limited. Future research could examine the gender issue in several male-dominated industries such as engineering, mining, and construction industry. Moreover, this study aimed at implications derived from female employees who are currently working in the manufacturing industry. Future research could extend the study by investigating the perceptions of female workers who are not working in factory to examine their perceptions or misconception towards male-dominated industry. Additionally, future study could also examine perceptions of female graduates towards male-favoured industry in order to identify the motivation and priorities for them to work in the industry. Finally, future research could look at the recruitment and selection process in manufacturing industry or other male-dominated sectors. There is a possibility that employers implicitly select job candidates based on competences in addition to cultural similarities in terms of shared experiences and self-presentation styles (Rivera, 2012). Such cultural reproduction (Bourdieu, 1984) not only reinforce masculine norm in the industry which are deeply rooted in cultural past but also leads to deficiency in gender diversity.

\section{References}

1. Arthur, W., Bell, S. T. and Villado, A. J. (2006), "The Use of PersonOrganization Fit in Employment Decision Making: An Assesment of Its Criterion Related Validity”, Journal of Applied Psychology, Vol. 91, No. 4, pp.786-801. https://doi.org/10.1037/0021-9010.91.4.786

2. Barbulescu, R. and Bidwell, M. (2012), "Do Women Choose Different Jobs from Men? Mechanism of Application Segregation in the Market for Managerial Workers", Organization Science, Vol. 24, No. 3, pp. 737 - 756. https://doi.org/10.1287/orsc.1120.0757

3. Bryman, A. (2012), Social Research Methods, 4th ed, Oxford: Oxford University Press.

4. Bourdieu, P. (1984), Distinction: A Social Critique of the Judgment of Taste, Cambridge: Harvard University Press.

5. Burke, S. and Collins, K. M. (2001), "Gender differences in leadership styles and management skills", Women in Management Review, Vol. 16, No. 5, pp.244-257. https://doi.org/10.1108/09649420110395728

6. Cable, D. M. and Parsons, C. K. (2001), "Socialization Tactics and Person Organization Fit", Journal of Personnel Psychology, Vol. 54, No. 1, pp.1-23. https://doi.org/10.1111/j.1744-6570.2001.tb00083.x

7. Carli, L. L. and Eagly, A. H. (2001), "Gender, Hierarchy, and Leadership: An Introduction", Journal of Social Issues, Vol. 57, No. 4, pp.629-636. https://doi.org/10.1111/0022-4537.00232 
8. Cordano, M., Scherer, R. F. and Owen, C. L. (2002), "Attitudes toward women as managers: sex versus culture", Women in Management Review, Vol. 17, No. 2, pp.51-60. https://doi.org/10.1108/09649420210421754

9. Correll, S. J. (2001), "Constraints into Preferences: Gender, Status, and Emerging Career Aspirations", American Sociological Review, Vol. 69, No. 1, pp.93-113. https://doi.org/10.1177/000312240406900106

10. Deloitte \& Manufacturing Institute, (2012), Women in Manufacturing Untapped resource: How manufacturers can attract, retain, and advance talentedwomen. [Online] Available from: http://www.themanufacturinginstitute.org/ /media/D0D064208A994D6A91B0E 51CF008BF23.ashx [Accessed 08 October 2014].

11. Erhardt, N. L., Werbel, J. D. and Shrader, C. B. (2003), "Board of Director Diversity and Firm Financial Performance", Corporate Governance - An international Review., Vol. 11, No. 2, pp.102-111.

12. Evetts, J. (1998), "Managing the technology but not the organization: women and career in engineering", Women in Management Review, Vol. 13, No. 8, pp.283-290. https://doi.org/10.1108/09649429810243144

13. Fernandes, E. and Cabral-Cardoso, C. (2003), "Gender asymmetries and the manager stereotype among management students", Women in Management Review, Vol. 18, No. 1/2, pp. pp.77-87. https://doi.org/10.1108/09649420310462352

14. Flabbi, L. (2010), "Prejudice and gender differentials in the US labor market in the last twenty years", Journal of Econometrics, Vol. 156, No. 1, pp.190-200. https://doi.org/10.1016/j.jeconom.2009.09.016

15. Jackson, J. C. (2001), "Women middle managers' perception of the glass ceiling”, Women in Management Review, Vol. 16, No. 1, pp.30-41. https://doi.org/10.1108/09649420110380265

16. Khoreva, V. (2011), "Gender pay gap and its perceptions”, Equality, Diversity and Inclusion: An International Journal, Vol. 30, No. 3, pp.233-248. https://doi.org/10.1108/02610151111124969

17. Kravitz, A. D. (2003), "More Women in the Workplace: Is There a Payoff in Firm Performance?" The Academy of Management Executive , Vol. 17, No. 3 pp.148-149. https://doi.org/10.5465/AME.2003.19198794

18. Kristof, A. L. (1996), "Person-Organization Fit: An integrative review of its conceptualizations, measurements, and implications", Journal of Personnel

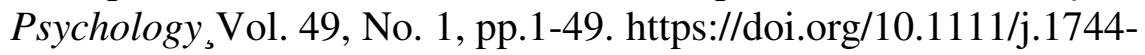
6570.1996.tb01790.x

International Journal of Management and Applied Research, 2015, Vol. 2, No. 1 
19. Lawthom, R., Patterson, M., West, M. and Staniforth, D. (1996), "Women managers' views of manufacturing: nice work?", Women in Management Review, Vol. 11, No. 6, pp. pp.3-10. https://doi.org/10.1108/09649429610127910

20. Lenard, M. J., Bing, Y., York, E. A. and Wu, S. (2014), "Impact of board gender diversity on firm risk", Managerial Finance, Vol. 40, No. 8, pp.787-803. https://doi.org/10.1108/MF-06-2013-0164

21. Levin, L. A. and Mattis, M. (2006), "Corporate and academic responses to gender diversity", Equal Opportunities International, Vol 25, No. 1, pp.60-70. https://doi.org/10.1108/02610150610645977

22. Lückerath-Rovers, M. (2013), "Women on boards and firm performance", Journal of Management \& Governance, Vol. 17, No. 2, pp.491-509. https://doi.org/10.1007/s10997-011-9186-1

23. Mousumi, R. (2009), "Blame Culture", In: C. Wankel, ed. Encyclopedia of Business in Today's World. Thousand Oaks: SAGE Publications Inc. pp.156158.

24. Office for National Statistics (2013), Full report - Women in the labour market. [Online] Available from: http://www.ons.gov.uk/ons/dcp171776_328352.pdf [Accessed 04 November 2014].

25. Peacock, L. (2011), "Engineering graduates choosing to work in other sectors", The Telegraph. [Online] Available from: http://www.telegraph.co.uk/finance/newsbysector/industry/engineering/8729050 /Engineering-graduates-choosing-to-work-in-other-sectors.html [Accessed 06 November 2014].

26. Piasentin, K. A. and Chapman, D. S. (2006), "Subjective person-organization fir: Bridging the gap between conceptualization and measurement", Journal of Vocational Behavior, Vol. 69, No. 2, pp.202-221. https://doi.org/10.1016/j.jvb.2006.05.001

27. Powell, A. B., Bagilhole, B., Dainty, A. and Neale, R. (2004), "Does the engineering culture in UK higher education advance women's career?", Equal Opportunities International, Vol. 23, No. 7/8, pp.21-38. https://doi.org/10.1108/02610150410787882

28. Raluca-Georgiana, M. (2013), "The Impact of Gender and Age Diversity on Company Performance", Knowledge Horizons, Vol. 5, No. 4, pp.215-219.

29. Rivera, L. A. (2012), "Hiring as Cultural Matching: The Case of Elite Professional Firms", American Sociological Review, Vol. 77, No. 6, pp. 9991022. https://doi.org/10.1177/0003122412463213 
30. Reskin, B. F. and Bielby, D. D. (2005), "A Sociological Perspective on Gender and Career Outcomes", Journal of Economic Perspectives, Vol. 19, No. 1, pp.71-86. https://doi.org/10.1257/0895330053148010

31. Rutherford, S. (2001), "Organisational cultures, women managers and exclusion", Women in Management Review, Vol. 18, No. 8, pp.371-382. https://doi.org/10.1108/EUM0000000006289

32. Saunders, M., Lewis, P. and Thornhill, A. (2012), Research Methods for business students. 6th ed. Harlow: Pearson.

33. Schwandt, T. A. (1997), Qualitive Inquiry - A Dictionary of Terms. Thousand Oaks: SAGE Publications, Inc.

34. Sharabi, M. and Harpaz, I. (2013), "Changes of work values in chaning economy: perspectives of men and women", International Journal of Social Economics, Vol. 40, No. 8, pp. 692-706. https://doi.org/10.1108/IJSE-01-20120018

35. Sherman, E. L. and Chatman, J. A. (2013), "Organizational Socialization”, In: E. H. Kessler, ed. Encyclopedia of Management Theory. Thousand Oaks: SAGE Publications, Inc. pp. 567-570.

36. Simpson, R. (2000), "Gender mix and organisational fit: how gender imbalance at different levels of the organisation impacts on women managers", Women in Management, Vol. 15, No. 1, pp.5-18.

https://doi.org/10.1108/09649420010310173

37. Tatli, A. (2006), "Handbook of Workplace Diversity", Equal opportunities international, Vol. 25, No. 2, pp.160-162.

https://doi.org/10.1108/02610150610679583

38. The World Bank (2014), Labor force, female (\% of total labor force). [Online]. Available from: http://data.worldbank.org/indicator/SL.TLF.TOTL.FE.ZS [Accessed 04 September 2014].

39. Tijdens, K. G. and Van Klaren, M. (2012), ITUC Report - Frozen in Time: Gender pay gap unchanged for 10 years. [Online] Available from: http://www.ituc-csi.org/frozen-in-time-gender-pay-gap.html?lang=de [Accessed 20 November 2014] 